\title{
Diploma to degree 1976 to 1993
}

\author{
Dr Richard C Price
}

\author{
Head of School \\ School of Health \& Emergency Professions \\ University of Hertfordshire \\ College Lane \\ Hatfield \\ Herts \\ AL10 9AB
}

\section{Abstract}

The debate on degree education for radiographers began in earnest in the mid-1970s. Initially the debate hinged around whether a degree education was necessary for radiographers. One argument was that it was felt that a degree would separate academic and clinical training but eventually when degrees were introduced practical skills were assessed formally for the first time; something that had not been achieved with the Diploma of the College of Radiographers (DCR).

The DCR itself became a barrier to degree education as the College of Radiographers (CoR) insisted that it was the only qualification recognised for state registration and as such would have to remain embedded as a distinct qualification within a degree.

A major breakthrough came when the Council for National Academic Awards (CNAA) recognised the DCR at the same level as an ordinary degree. Around the same time the CoR published its Degree Rationale which announced a change in policy by not insisting that the DCR was sacrosanct.

Developments followed rapidly and the first honours degree in radiography was validated in 1989 despite opposition from scientific officers at the Department of Health. Degrees were approved for state registration and radiography became a graduate profession by 1993 following years of debate and after overcoming opposition from both within and external to the profession.

\section{Key words.}

Radiography degrees, radiography education development.

\section{Introduction}

This article provides a narrative account of steps taken towards establishing Radiography as a graduate profession. Articles, archive material from the College of Radiographers (CoR), the Council for Professions Supplementary to Medicine (CPSM) and material collected by the author for the 1995 Melville lecture provide the main sources of information. The opinions expressed are those of the author alone and of no other person or organisation. 


\section{Thoughts of degrees}

While there is room for debate when the first moves towards degree education began, this article picks up the story from 1976 when The CPSM, the forerunner to the Health Professions Council (HPC), considered it was time to consider future educational policy. It set up the Higher and Further Education Working Party with a remit to review:

"the opportunities and constraints upon, the collaboration between the health and education services and the professions supplementary to medicine in vocational education and training; ..... for ensuring that such education and training is effective and efficient ......"

Representatives from each of the CPSM Boards together with assessors from the health and education departments of the four United Kingdom (UK) countries formed the working party. The inclusion of the education department was interesting as education for the professions supplementary to medicine was the responsibility of the health department. "The Next Decade"1 was published in 1979 with nearly sixty recommendations including the transfer of funding from health to the education with integration of schools into higher education. The report was not supported outside the working group and, crucially none from the Department of Health and Social Security (DHSS). The College of Radiographers (CoR) did not support the report but their were more to do with the fact they were unrepresented on the working party and were suspicious that the CPSM wanted to extend its influence over post registration qualifications. The report faded into obscurity but it cannot be denied that it was imaginative and ten years ahead of its time but many of the recommendations have since been realised.

Nevertheless the CoR's thoughts had turned towards degrees and radiographers were beginning to set out their thoughts. Bentley ${ }^{2}$ was instrumental in setting out the differences between a degree and a diploma. He proposed a degree course of four years and five months; students were to sit a final university examination in May of the fourth year and the Diploma of the College of Radiographers (DCR) Part II in the following October. England and Grimshaw ${ }^{3}$ were critical; they felt it was comprehensive but asked what graduates would do as basic grade radiography would be below students' expectations. However their proposal for an advanced diploma was based on three years full time study to attain the DCR and then to progress to the Higher Diploma of the College of Radiographers (HDCR) or follow options in ultrasound, nuclear medicine or teaching. In any event, students would have to obtain the HDCR before progressing to an Advanced Diploma of the College of Radiographers. This option, rather than bringing higher education to radiographers placed it further out of reach. Sepion ${ }^{4}$ supported England and Grimshaw's principle but suggested that it would not be provident for the College to take total charge. He proposed that the Open University award degrees at bachelor, masters and doctorate level but a first degree could not be awarded until the HDCR was attained. Jones and Weatherburne ${ }^{5}$ argued that it would be desirable for some radiographers to attain graduate status as this would enhance the profession but suggested a modular approach with the HDCR as a core module to provide the academic content which could not be attained with DCR because of its practical nature.

While the debate continued, the CoR pursued two initiatives, an MSc in radiation sciences with the North East London Polytechnic and an undergraduate degree with Llandaff 
Technical College. The Llandaff initiative involved consultation with the Welsh Office and the DHSS.

The attitude of the DHSS was revealed in a letter ${ }^{6}$ to the CoR in June 1979.

"Degree courses for radiographers at any level appear to overlap into the fields of training and competence of the medical radiologist or the medical physicist/ electronic engineer.

There seems only the most limited scope in radiography for the academic orientation of degree training, and this would not seem to justify degrees replacing the acceptable alternative post registration training already available.

It would be difficult to keep a balance between the academic and vocational training in radiography between diplomates and graduates without further lengthening of training, with no real benefit to the NHS."

It concluded:

"From the above you will deduce that even if some degree provision was considered desirable we see considerable difficulties ahead but nevertheless I am willing to meet representatives of the College for an informal, without prejudice, preliminary discussion."

(DHSS, June 1979)

According to Jordan ${ }^{7}$ the end came because the Welsh Office and the DHSS destroyed the initiative by raising insurmountable difficulties and leaving Llandaff no alternative but to withdraw their proposal.

It was understandable if the CoR were frustrated by a lack of success as the recognition of the first degree in physiotherapy at the New University of Ulster was in 1976. This had not been a straightforward affair. Strong opposition had been mounted by the DHSS but help came from the medical profession. The degree had been validated by the Council for National Academic Awards (CNAA) the largest degree-awarding body in the UK, and was supported by the Physiotherapists Board at the CPSM. However, it was refused recognition by the Privy Council which was acting in an extraordinary fashion according to Carron Brown $^{8}$, a CPSM council member and vice-chairman, who stated that the Privy Council was acting on behalf of the DHSS who seemed to fear that degree courses would be expensive. Mr Carron Brown and another medical member of the PSM Council did not agree and mobilised the Royal Colleges into action in support of the degree. The DHSS backed down and the degree was approved for state registration. A precedent had been established but was it going to open the door for radiography?

There was opposition to degrees from within the profession and in 1980 the London and Home Counties Branch produced a paper on the future of the $\mathrm{DCR}^{9}$. It put forward the position that a basic radiographer's position does not justify a degree qualification, and would increase the separation of academic and practical training. Their view was that the DCR be retained as the basic professional qualification but count as credit towards a degree. Further credits would be gained by an intermediate HDCR consisting of a compulsory theory module and an elective combination of modules in diagnostic radiography, radiotherapy, ultrasound, nuclear medicine, management and teaching. A degree would occupy the 
summit of a tiered progression of qualifications; in reality the proposal offered nothing new from previous complicated proposals.

In 1983 the CoR was in discussion with London University to discuss the HDCR as an entry requirement for the MSc in Radiation Science. The University was reported to have said that HDCR questions were probably too elementary to substitute for a BSc and to satisfy regulations for MSc radiographers would need the HDCR and enter a special examination based on BSc level. This initiative did not make any progress.

\section{An unfortunate episode with the CNAA}

A letter sent in December 1986 from the CNAA to polytechnics encouraging the establishment of post registration courses for the professions allied to medicine provided. The CNAA would consider validating honours degrees for members of the professions provided they could meet specified entry requirements. The list included a degree; diploma of higher education and other qualifications the CNAA deemed acceptable. These included the Diploma of the College of Occupational Therapists; Diploma of the College of Speech Therapists; Diploma of the British Orthoptic Society; Diploma in Dietetics; Membership of the Chartered Society of Physiotherapy, Membership of the Society of Chiropodists and HDCR In addition, entrants would have to have at least one year of post-registration practical professional experience.

The DCR was not recognised at the same level as entry qualifications for the other professions. Whereas, physiotherapists or occupational therapists qualification would attract 240 credit and accumulation transfer (CATS) points, the value attributed the DCR was zero.

When challenged, the CNAA's ${ }^{10}$ response included the following statements:

"The decision on which qualifications were deemed acceptable for the purposes of the Council's Regulation 8.17 (c) was based upon a number of factors of which the following are the most important.

(i) the stated entry qualifications and the profile of entrants to the qualification under consideration.

(ii) the acceptability as entry requirements or as the basis for admission with advanced standing by universities, including the Open University.

(iii) experience concerning the admission and success of these qualifications on CNAA courses.

(iv) most importantly, a judgement concerning the academic content of qualifications. In the case of radiography, the academic content of the Diploma was considered to be insufficient. However, the extra academic content in the Higher Diploma led to its inclusion on the list."

The CNAA could be forgiven for not recognising the DCR at pass degree level when the CoR itself had indicated that the HDCR be a perquisite for a first degree. There was a suspicion that the CNAA based its decision on the old two year syllabus. Up to date information was sent to the CNAA and they were asked to reconsider their position. They did and the DCR was recognised as equivalent to 240 CATS points. This was a significant 
breakthrough and was to ease the way ahead but the CoR would have to reconsider its stance over the HDCR.

\section{Criticism of the College of Radiographers}

Merriman ${ }^{11}$ was critical of the lack of progress towards degrees and cited developments in the other professions allied to medicine. He was annoyed that the other paramedical professions rapidly outstripping radiography in status, credibility and influence. He felt it was ironic that a physiotherapy lecturer could enrol for an MSc without having to undergo anything equivalent to the HDCR and TDCR. Merriman was critical that his TDCR took seven years to achieve and academically was inferior to a BSc in Physiotherapy. Some positions, however, were unshakable and while Bentley and Watson ${ }^{12,13}$ produced a cogent argument for degrees, maintained the view that the DCR was necessary for state registration. This had always been the stumbling block and was recognised as such by Merriman who challenged the CoR to decide whether its system of examinations was appropriate.

Unknown to Merriman matters attitudes were changing. A series of CoR Special Council meetings from the mid-1980s placed education high on the agenda and enabled Council to clarify its position. In 1986 the College did affirm its commitment to degree level education and charged the Future Training and Degree Sub Committee with the task of articulating the policy. This resulted in the Degree Rationale ${ }^{14}$ launched in September 1987 which issued a challenge to schools of radiography:

"To make progress the College of Radiographers would welcome initiatives from individual training centres and degree awarding bodies. The College would collaborate with institutions on the basis of providing joint validation."

Degree Rationale

This was an about turn in policy. The cornerstone of policy had been preservation of the DCR. For the first time the CoR acknowledged that if degree level education was to be achieved it would have to give up its central control over the syllabus and examinations. Curriculum development would be devolved to local centres but the CoR would want to develop a role as a validating body in which it would function conjointly with awarding institutions. However, the CoR was not ready to let go completely as was evident by developments in Ireland.

\section{An Irish venture}

While discussions were taking place with the CNAA, the CoR and the Radiographers Board were involved in discussions with the School of Radiography at St Vincent's Hospital and University College, Dublin over the provision of a degree. An agreement was reached which exempted students from sitting Part I of the DCR but students had to take Part II of the DCR as well as University final examinations. The examinations were exactly the same format and level as the DCR.

It was at the insistence of the CoR and the Radiographers Board that the DCR Part II was maintained. Perhaps insistence is too strong a word as it would be impertinent for British institutions to instruct an organisation in another country what to do. Nevertheless that was the situation and the Irish went along with it. Although giving ground on part I of the DCR the 
CoR remained intransigent and was not going to give ground on DCR completely, at least not at that time. The Radiographers Board on the other hand were also being guarded but it was more difficult to understand their position. It could be said that the Board was acting outside its authority which rested in the Professions Supplementary to Medicine Act 1960. The Act had no standing in Ireland; the Irish state was free to recognise whatever education it determined to be appropriate for radiographers. But the Irish were compliant with the requests of the British with whom they had always aligned themselves educationally and professionally. Nevertheless, the first radiography degree in British Isles had been achieved. Despite the students having to take a double dose of final examinations it was not to be a deterrent to recruitment as the Bachelor of Radiography became one of the most popular courses at University College.

\section{Trouble at the Department of Health (DH)}

The push for degree education on the home front was gathering momentum; a number of schools of radiography were taking up the challenge set out in the Degree Rationale. However, there was strong opposition to degrees from the Chief Scientific Officer at the DH together with regional scientific officers who wanted radiography to be undertaken by imaging technicians ${ }^{15}$. A series of difficult meetings in 1989 between the CoR failed to produce a resolution and on one occasion Peter Smith, the CoR's Director of Education, who had at the forefront of degree education was refused entry to a meeting at the $\mathrm{DH}^{7}$. However, the scientific officers' position was tenuous as in 1989 the $\mathrm{DH}$ published a white paper, 'Working for Patients' where Working Paper $10^{16}$ outlined proposals for regional health authorities to purchase education and training for the professions. The RHAs signalled that they wanted to purchase courses from higher education institutions. This put pay to any real opposition from the scientific officers.

In any case the CoR had not been deterred and continued to support developments giving a clear signal that the DCR was no longer a barrier. However, the role of the Radiographers Board was to be crucial; a body that worked on precedent had to deal with situations that had no precedents. After thirty years of recognising the DCR, they were being asked to approve alternative qualifications. Nevertheless, in October $1989^{17}$ under the chairmanship of Pamela Kimber, they took a landmark decision to support the principle of degrees.

"After discussion it was agreed in principle that degree based training was an appropriate vehicle for the conveying of sufficient knowledge and skill in radiography and these submissions for duly validated degree courses should be put to the Board and Council in due course for approval as leading to state registration."

\section{Goal Achieved}

The first validation of a radiography degree in the UK was at Portsmouth Polytechnic in December 1989. The BSc (Hons) in Radiography degree was duly validated with CoR and Board representatives present but it remained to be seen how the Board would respond formally. The Board considered the validation outcome in January 1990 and set a precedent by the advising the Council that the BSc (Hons) in Radiography at Portsmouth Polytechnic met the criteria for state registration purposes as laid down in the Professions Supplementary to Medicine Act $1960^{18}$. Following this recommendation the Board held a 
number of special meetings to consider other submissions. The Radiographers Board recommendations' were critical as without them the qualification could not be passed through the CPSM for transmission to the Privy Council who were required to give the final approval. It ought to have been a reasonable assumption that once a degree course had been through the rigours of validation and approved by the radiographers Board that Privy Council approval would follow. But this was not the case in a number of instances. Once forwarded to the Privy Council, further advice was sought from the Department for Education and Science and the Department of Health. This was not an open process and one is left to speculate why some courses were not approved, however, these proved to be temporary set backs. Radiography moved to an all graduate entry profession by 1993.

The CoR's role in education changed from the central examining body to one that acted in partnership with other bodies to approve degree course. At undergraduate level the formation of the Joint Validation Committee with the Radiographers Board was a sensible move which provided a unified professional approach to education.

\section{Conclusion}

The possibility of radiography degrees had been debated long and hard before becoming reality. The profession had been unsure as to whether it was the right path to take. Some were of the view that the role of the radiographer did not warrant degree education, clearly a failure to value their profession. Others believed that degrees would separate academic and practical training but the reality was that degree courses introduced clinical assessment which had never been part of the DCR.

The DCR itself was the major barrier to progress for a number of years with the CoR refusing to compromise its status as the only UK qualification approved for state registration. Also by signalling that the HDCR should be a prerequisite for radiographers to undertake a degree this only lowered the perceived status of the DCR by external organisations. This was the case when the CNAA recognised the DCR at a lower level than the qualifications of the other professions allied to medicine. Justice was done when the CNAA reversed its decision and parity was achieved. A major catastrophe which would have set back the profession's graduate aspirations, possibly, for years had been avoided. However, it still needed the CoR to relax its policy on the DCR which it did in effect with the publication of the Degree Rationale. Once one school had decided to develop a degree it was clear that the others would follow.

Twenty years on from the validation of the first radiography degree, the profession's education is firmly established in higher education. The BSc (Hons) is the threshold for HPC registration as a Radiographer. Many radiographers study for masters' degrees and doctorates. Looking back one is tempted to ask what was all the fuss about?

\section{Acknowledgments}

Thank you to the College of Radiographers and the former CPSM for access to their archive material.

\section{References}

1. The Higher and Further Education Working Party. The next decade. London: CPSM; 1979. 
2. Jordan RM. The maturing years. London: The Society and College of Radiographers; 1995.

3. Bentley H. BA degree course for radiographers. Radiography 1977;XLIII:231e4.

4. England I, Grimshaw M. Radiographers and a degree. Radiography 1978;XLV:261-2.

5. Sepion E. St C. Educational degrees for radiographers. Radiography 1979;XLV. p. 50.

6. Jones G, Weatherbourn H. Degree level courses for radiographers. Radiography 1979; $\mathrm{XLV}: 69-71$.

7. College of Radiographers Archive. Letter from the DHSS to Michael Jordan, Secretary, 18th June 1979.

8. Brown Carron. J Personal communication; 1995.

9. Platt SE, Matthews M, Perera TW. Discussion Document. Is the product of our training system satisfactory for our needs? 1980 College of Radiographers archive.

10. Letter from Dr M Frazer Chief Executive, CNAA to R Price Chairman Education \& Training Committee, College of Radiographers 1987. Personal communication.

11. Merriman G. Radiography training: it's all a question of degrees. Radiography 1987;53:211e3.

12. Bentley HB, Watson A. A proposed scheme for a first degree in radiographic imaging science (part 1). Radiography 1987;53: 214-6.

13. Bentley HB, Watson A. A proposed scheme for a first degree in radiographic imaging science (part 2). Radiography 1988; 54: 31-4.

14. The College of Radiographers. Report from a special council meeting. June 1986.

15. The College of Radiographers. Degree rationale. London: The College Of Radiographers; 1987.

16. Price R. Presidential address e coming in from the cold. Radiography Today 1990;56:1217.

17. Department of Health. Working for Patients, Education and Training, Working Paper 10. 1989. London HMSO.

18. Minutes of the Radiographers Board 29 January 1990.

19. Burley P. J Personal communication; 1995.

20 Eraut M. Developing professional knowledge and competence. London: The Falmer Press; 1994 